\title{
NeuroRegulation
}

\section{Neurofeedback: An Examination of Attentional Processes in Adults with Self-Reported PTSD Symptoms}

\author{
Lelah S. Villalpando ${ }^{*}$, Connie J. McReynolds ${ }^{2}$, Grace Lee ${ }^{1}$, Susanne Montgomery ${ }^{1}$, and David \\ Vermeersch ${ }^{1}$
}

${ }^{1}$ Loma Linda University, Loma Linda, California, USA

${ }^{2}$ California State University, San Bernardino, San Bernardino, California, USA

\begin{abstract}
Novel, effective, and accessible therapeutic interventions for treating posttraumatic stress disorder (PTSD) symptoms are in demand given the significant physical and psychosocial impairment associated with the disorder. Although PTSD is largely treated with cognitive behavioral therapy (CBT), treatment resistance, or nonresponse rates, continues to remain high. Research has shown talk therapies can trigger the limbic system, keeping it in a continual state of fight or flight. Consequently, many trauma survivors seek alternative treatments, such as EEG neurofeedback training. This study explored the relationship between trauma-related symptoms (i.e., inattention and impulsivity) and visual and auditory functioning in a population of veterans and nonmilitary adults who reported previously being diagnosed with PTSD by a mental health clinician. Results suggest that EEG neurofeedback therapy is clinically effective for improving visual and auditory attentional functioning in both veterans and nonmilitary adults. Improved attentional functioning is believed to boost organizational skills, decision-making, frustration tolerance, and comprehension. This is important given that two-thirds of veterans who complete CBT programs remain in the clinical range for PTSD with notable attention deficits. Treatment outcome research, such as this study, is vital to improve the effectiveness of therapeutic interventions for persons diagnosed with PTSD, particularly within specific populations that have high nonresponse rates, such as veterans.

Keywords: posttraumatic post disorder (PTSD); auditory processing; visual processing; neurofeedback; IVA-2 Continuous Performance Test

Citation: Villalpando, L. S., McReynolds, C. J., Lee, G., Montgomery, S., \& Vermeersch, D. (2020). Neurofeedback: An examination of attentional processes in adults with self-reported PTSD symptoms. NeuroRegulation, 7(4), 142-155. https://doi.org/10.15540/nr.7.4.142

*Address correspondence to: Lelah S Villalpando, PhD Candidate, Loma Linda University, School of Behavioral Health, Department of Psychology, 11130 Anderson Street, Loma Linda, CA 92350, USA. Email: villalpando.lelah@gmail.com

Copyright: ( 2020. Villalpando et al. This is an Open Access article distributed under the terms of the Creative Commons Attribution License (CC-BY).

\author{
Edited by: \\ Rex L. Cannon, PhD, SPESA Research Institute, Knoxville, \\ Tennessee, USA \\ Rex L. Cannon, PhD, SPESA Research Institute, Knoxville, \\ Tennessee, USA \\ Genomary Krigbaum, PsyD, University of Wyoming, Family Medicine \\ Residency, Casper, Wyoming, USA
}

Reviewed by:
\end{abstract}

\section{Introduction}

During any given year, approximately eight million people in the U.S. meet criteria for posttraumatic stress disorder (PTSD). Although PTSD is gaining more public attention, treatment-resistant PTSD is not as widely talked about (Feduccia \& Mithoefer, 2018). Approximately $70 \%$ of the world's population has been exposed to some type of traumatic event, with $5.6 \%$ meeting DSM-5 criteria for PTSD (Bomyea \& Lang, 2012). Commonly used interventions for treating PTSD include various types of cognitive behavioral therapies (CBT), such as cognitive processing therapy (CPT), trauma-focused cognitive behavioral therapy (TF-CBT), and eye movement desensitization and reprocessing (EMDR). Although these interventions may be equally effective, there is a high dropout rate for these treatments, as well as high nonresponse rates (Litz et al., 2019).

Electroencephalographic (EEG) neurofeedback training is a readily available treatment that has been identified as effectively reducing PTSD symptoms by training individuals to self-regulate brainwave frequencies (La Marca et al., 2018; 
Panisch \& Hai, 2020). Neurofeedback therapy is administered through a brain-computer interaction $(\mathrm{BCl})$ device, which provides a structured training program tailored to each participant. $\mathrm{BCl}$ devices have been used in a variety of settings and applied to diverse populations over the past three decades. For example, $\mathrm{BCl}$ devices utilizing neurofeedback therapy are used in physical rehabilitation hospitals to improve cognitive functioning in patients with a history of stroke and dementia (da Silva-Sauer, de la Torre-Luque, Silva, \& Fernández-Calvo, 2019). In addition to physical disability, EEG neurofeedback is often used for performance enhancement or to treat clinical conditions, such as learning and memory, sustained attention, sleep, ADHD, PTSD, depression, and anxiety (van der Kolk et al., 2016).

Novel, effective, and accessible therapeutic interventions for treating PTSD symptoms are in demand at unprecedented levels given the significant physical and psychosocial impairment associated with the disorder, and the burden placed on both the individual and the healthcare system, including rising costs for ongoing care, loss of work, and disability benefits. In 2012, the VA spent approximately $\$ 3$ billion and the Department of Defense (DOD) spent about \$294 million on PTSD care for service members and veterans (Institute of Medicine, 2014).

\section{Neurofeedback Therapy}

The brain's activity determines the way a person experiences the world; everything that is felt and expressed is motivated by the sensory system. Neurofeedback therapy, or EEG biofeedback, was first introduced in the late 1950s by scientists who discovered that brain wave activity could be manipulated by using a simple reward system (Fisher, Lanius, \& Frewen, 2016). Further studies indicated that modulating brain activity provided long-term neural-network stability and neuroprotection against various toxins and neurodegeneration (da Silva-Sauer et al., 2019). Neurofeedback therapy has gained recognition as an appropriate intervention for conditions ranging from PTSD, ADHD, learning disabilities, and emotional dysregulation (Hammond, 2011; McReynolds, Bell, \& Lincourt, 2017; McReynolds, Britt \& Villalpando, 2019; McReynolds, Villalpando \& Britt, 2018).

To understand neurofeedback, and how it trains the brain using biofeedback, it is imperative to understand the basic fundamentals of brain waves.
Brain waves are electrical impulses that fire when neurons communicate with each other (Broderick, 2015). Brain waves tell the story of how a person's brain is functioning, such as thought habits, mood, and stress levels. During a neurofeedback training session, brain waves indicate whether or not an individual is in a comfortable state (Fisher et al., 2016; McReynolds et al., 2017). The biofeedback generated on a computer screen showing brain activity will respond with a reward (e.g., video games, music, sound bites) when the brain waves indicate a desired state of arousal has been achieved. With repetition, much like exercise, the neural pathways are strengthened and trained to learn how to self-correct brain activity from a heightened state of arousal and inattention to a more relaxed state and better able to attend to external sensory stimuli (Butko \& Triesch, 2007; Vignoud, Venance, \& Touboul, 2018). Research indicates that individuals may experience an improvement in language and learning when sensory processing pathways are structurally strengthened (Boscariol et al., 2010). Additionally, studies have produced evidence that neurofeedback training may enhance neuroplasticity (Hammond, 2011; Quevedo et al., 2019).

\section{Posttraumatic Stress Disorder}

PTSD is a survival response pattern that occurs when a person has been exposed to actual or threatened death, serious injury, or sexual assault. It is characterized by nightmares, anxiety, fear in the absence of danger, recurrent re-experiencing of the event, avoidance of reminders of the trauma, emotional numbing, hyperarousal, and trouble concentrating (Feduccia \& Mithoefer, 2018; Table 1).

The term known today as PTSD has been around for about 40 years, after it appeared in the 1980 version of the DSM-III. PTSD has been known by many different names throughout history, such as "combat hysteria," "shell shock," "soldier's heart," "battle hypnosis," and "war neurosis" (Crocq \& Crocq, 2000). Psychiatrists in the early 1900s began comparing the behavioral traits of World War I soldiers with civilians who witnessed mass casualty man-made disasters (e.g., railway disasters following the introduction of steam-driven machinery during the Industrial Revolution). To the surprise of psychiatrists, they found similarities between cases of soldiers who had "war neurosis" and civilians who witnessed the man-made disasters. Similar symptoms identified among both soldiers and civilians were anxiety, fright brought about by loud 
Table 1

DSM-5 General Diagnostic Criteria for PTSD

A. Exposure to actual or threatened death, serious injury, or sexual violence in at least one of the following ways:

1. Directly experiencing a traumatic event

2. Being a firsthand witness to a traumatic event

3. Learning a traumatic event has occurred to a close family member or friend

4. Experiencing repeated or extreme exposure to aversive details of traumatic events

B. Presence of at least one of the following intrusion symptoms that begin after the event occurred:

1. Recurrent, involuntary, and intrusive distressing memories of the traumatic event(s)

2. Recurrent distressing dreams that are related to the traumatic event(s)

3. Flashbacks

4. Intense or prolonged psychological distress when exposed to internal or external cues that resemble an aspect of the traumatic event(s)

C. Persistent avoidance of things associated with the traumatic event(s), beginning after the event (e.g., thoughts, feelings, people, places, activities, objects, situations)

D. Negative alterations in cognitions and mood associated with the traumatic event(s):

1. Inability to remember important parts of the traumatic event(s)

2. Persistent and exaggerated negative beliefs or expectations about oneself, others, or the world

3. Persistent distorted cognitions about the cause or consequences of the traumatic event(s) that lead to blaming self or others

4. Persistent negative emotional state (e.g., anger, guilt, fear)

5. Markedly diminished interest in important activities

6. Feelings of detachment from others

7. Persistent inability to experience positive emotions (e.g., happiness, satisfaction, or loving feelings)

E. Marked alterations in arousal and reactivity associated with the traumatic event(s):

1. Irritable behavior

2. Reckless or self-destructive behavior

3. Hypervigilance

4. Exaggerated startle response

5. Problems with concentration

6. Sleep disturbance

F. Duration of symptoms is more than one month

G. The symptoms cause significant distress in social, occupational, or other important areas of functioning

$\mathrm{H}$. The symptoms are not attributable to the effects of a substance or medical condition

Source: American Psychiatric Association, DSM-5, 2013.

sounds, nightmares, sudden muteness, deafness, tremors, and personality changes. By mid-20th century, psychiatrists understood the urgency for immediate treatment of "traumatic neurosis" symptoms, learning from WWI that when left untreated this condition could evolve into chronic and irreversible forms of somatic and psychological symptoms (Crocq \& Crocq, 2000).

Persons with PTSD show high levels of both impulsivity and inattention. Being in a state of chronic hypervigilance creates strong thought patterns, or neural connections, of fight or flight; perceiving a threat of danger when there is no actual threat (Fisher et al., 2016). Neurofeedback helps regulate emotional and mental states through upregulation of the prefrontal cortex, which leads to down-regulation of the amygdala (Herwig et al., 2019). While in this constant state of arousal, focused on negative and unpleasant perceived stimuli, an individual may miss other important pieces of information (e.g., pleasant and/or neutral stimuli) necessary to self-regulate.

\section{Auditory Processing Difficulties}

Auditory processing is much more than a measure of a person's hearing ability; it is the way in which auditory information is received and interpreted specific to auditory sensory pathways (Taneja, 2017a). Auditory processing is a fundamental component of communication. One of the important roles auditory processing plays in communication is phonological awareness, in which sounds are linked to letters, letters are encoded to form words, and words form sentences. Once all of this information has been processed and interpreted, the receiver can use the information to form a response. When the auditory processing system is impaired, as is often the case in persons struggling with PTSD, 
information heard is often not interpreted accurately (Solberg Økland, Todorović, Lüttke, McQueen, \& de Lange, 2018).

Auditory processing difficulty (APD) does not pertain to hearing loss as measured in standard audiological screenings; rather, it is the manner in which the brain processes auditory stimuli (McReynolds et al., 2018; McReynolds et al., 2019). APD can be identified at any age. Causes can be either developmental or acquired through TBI, stroke, neurodegeneration, exposure to neurotoxic substances, or even aging (Musiek et al., 2010; Taneja, 2017b). Reportedly, approximately $5 \%$ of school-aged children and $76 \%$ of adults struggle with some level of impaired auditory processing (Taneja, 2017b).

Although the underlying etiology of APD is controversial, deficits in performance are well documented including difficulty comprehending speech in the presence of background noise (Choudhury \& Sanju, 2019; McReynolds et al., 2018; McReynolds et al., 2019; Thomas \& Mack, 2010). Individuals with APD have difficulty identifying phonemes and linking them to their representative letters, which subsequently interferes with comprehension and storage of information being received through auditory channels (Thomas \& Mack, 2010). This chronic distortion of information on a daily basis can negatively impact quality of life, effective communication, academic success, and overall mental health and well-being. Studies have shown people with APD often experience significant levels of frustration, irritability, and clinical depression (Serafini, Engel-Yeger, Vazquez, Pompili, \& Amore, 2017).
Impaired auditory processing makes it difficult to attend to target stimuli (e.g., conversations, spoken instructions, introductions to new people) in the presence of competing background noise. Processing auditory information is quite complex, involving both serial and parallel processing (i.e., the dorsal stream processes spatial information and the ventral stream processes nonspatial information, respectively; Li et al., 2018; Recanzone \& Cohen, 2010). The auditory system involves shared processing with higher order cognitive structures and other sensory systems (e.g., executive functioning, memory, language, and attention). APD is manifested in a myriad of ways and may have different presentations in each individual due to the complex nature of the auditory nervous system.

Since the brain uses multiple sensory systems that work together to process information (Ghazanfar \& Schroeder, 2006), APD symptoms often overlap with those observed in individuals with other sensory deficits, such as visual processing difficulties (Musiek et al., 2010), and are also prevalent in PTSD populations (McReynolds et al., 2017; see Table 2 for examples of identified difficulties in individuals with APD).

\section{Visual Processing Difficulties}

Visual processing is not a measure of nearsightedness or farsightedness, rather it is the manner in which the brain, not the eyes, processes visual stimuli (McReynolds et al., 2018). Visual processing involves comprehension of visual information, such as written letters, symbols, images, and spatial localization of objects (Janarthanan, 2017).

\section{Table 2}

\section{Symptoms of Auditory Processing Difficulties}

- $\quad$ Poor listening skills (e.g., frequently being told to pay attention when requests are being made)

- Miscommunication that causes problems with partners, family, friends, and co-workers

- Difficulty following verbal multi-step directions that result in stress at home and work, due to failing to complete seemingly simple routine tasks

- $\quad$ Listening to the television at a high volume, but still having difficulty understanding what is going on

- Easily distracted by background sounds in the environment

- Difficulty following long conversations (e.g., feeling as though something was missed)
- Difficulty following conversations among a group of people (e.g., trouble distinguishing and tracking content of multiple conversations, as well as difficulty task switching between listening and responding)

- Trouble understanding verbal math problems, even though written math skills may be strong

- Difficulty remembering spoken information (e.g., frequently asking others to repeat what was said)

- Difficulty taking notes and/or summarizing spoken content

- Difficulty in focusing, sustaining, or dividing attention

- Difficulty with reading and/or spelling

Source: DeAngelis, 2018; McReynolds et al., 2017; Thorne \& Debener, 2014. 
Visual processing difficulties (VPD) is the brain's inability to accurately process visual stimuli (McReynolds et al., 2018; McReynolds et al., 2019). Similar to the auditory processing system, the visual processing system is highly complex, involving other sensory structures and higher order cognitive processing (Ghazanfar \& Schroeder, 2006). As such, VPD may be misdiagnosed or go undetected all together when relying solely on standard vision screens (Janarthanan, 2017). Symptoms of VPD frequently overlap with those observed in individuals with other sensory difficulties, such as, auditory processing difficulties (Musiek et al., 2010), and are often found in persons with PTSD (McReynolds et al., 2017; see Table 3 for examples of identified difficulties in individuals with VPD).

There are eight types of visual processing concerns that have been identified by neuroscientists; individuals can have one or more at the same time (Janarthanan, 2017). People who score low in visual processing on the Integrated Visual and Auditory Continuous Performance Test - Version 2 (IVA-2 CPT) may manifest some of the following symptoms.

\section{Visual perception concerns}

Individuals with this type have a difficult time distinguishing the difference between similar letters, symbols, shapes, or objects. During reading and writing tasks, an individual may have trouble with letters such as $d$ and $b$ or $p$ and $q$ (Janarthanan, 2017).

\section{Visual figure-ground discrimination concerns} Individuals with this type have trouble pulling contours and shapes from the contextual background. This makes it difficult to identify a specific piece of information on a piece of paper, which may cause an increase in anxiety (Janarthanan, 2017).

\section{Visual sequencing concerns}

Individuals with this type struggle with interpreting the order of words, images, and symbols. This makes reading a frustrating task because words and letters may become misinterpreted or reversed, and lines are often skipped or repeated (Janarthanan, 2017).

\section{Visual-motor handling concerns}

Individuals with this type have trouble coordinating visual feedback with execution of body movements. For example, it would be difficult to copy an image from a book because the image would be perceived, interpreted, and replicated based on distorted visualmotor processing abilities. Other identifying markers for visual-motor handling deficits are clumsiness and bumping into things (Janarthanan, 2017).

Long- or short-term visual memory concerns Individuals with this type may have difficulty remembering things that were initially perceived visually. This can make it hard to recall anything that was read, such as details of a story or detailed instructions (Janarthanan, 2017).

\section{Visual spatial concerns}

Individuals with this type have problems identifying the spatial localization of objects in relation to self and other objects. This makes it difficult to interpret maps and keep track of time (Janarthanan, 2017).

\section{Visual closure concerns}

Individuals with this type have trouble decoding an object if it is missing a part or a drawing that is not complete, such as a bus missing tires or a picture of a person without facial features. This creates problems with spelling and reading because the predictive nature of visual information processing is obstructed if a word is missing a letter (Janarthanan, 2017).

\footnotetext{
Table 3

Visual Processing Difficulties

- Easily distracted by irrelevant visual stimuli

- Difficulty extracting meaning and emotion from written communication and images (e.g., emails, texts, written instructions, signs, pictures)

- $\quad$ Trouble with visuo-spatial object rotation and distance perception, which makes things like map reading and catching a ball difficult (i.e., identifying oneself in relation to another object)

- Difficulty remembering written information (e.g., appointments, payment due dates, information on flyers, lists)

- Difficulty following written multi-step directions that result in stress at home and work, due to failing to complete seemingly simple routine tasks (e.g., making/completing to-do lists, reading/following instruction manuals, making a grocery list but forgetting it at home and not remembering what was on it)
}

Source: McReynolds et al., 2018; Sandford \& Sandford, 2015. 


\section{Letter and symbol reversal concerns}

There are two types of reversal deficits, static reversals and kinetic reversals. Static reversals occur when letters are written in the wrong direction (e.g., b and d; $p$ and q; 5 and 2). Kinetic reversals occur when words are written as a mirror image of the target word (e.g., ton, not; was, saw). Letter and symbol reversal production usually resolves around age 7 (Janarthanan, 2017).

\section{Research Hypotheses}

The purpose of this study is to evaluate the clinical effectiveness of neurofeedback therapy on various trauma-related symptoms-specifically, response control and impaired attention-by measuring visual and auditory functioning in adults with PTSD who either reported having military background or no military background. It was hypothesized that the IVA-2 CPT, a global measure of visual and auditory processing, would show a significant improvement in response control and attention after 20 sessions of training. It was also hypothesized that there would be no difference in treatment outcomes among military and nonmilitary adults with PTSD symptoms, as measured by the Prudence and Vigilance scales.

\section{IVA-2 CPT Assessment Tool}

The IVA-2 CPT provides a $\mathrm{BCl}$ diagnostic tool for trained clinicians to identify visual and auditory processing deficits, as well as strengths. Test-retest reliability has been established, with a reported range of $0.66-0.75$ for auditory quotient scores (inattention) and $0.37-0.41$ for response control quotient scores (impulsivity; Sandford \& Sandford, 2015). To date, research has not widely established a correlation between visual and auditory processing difficulties and the role they play in an individual's susceptibility to developing PTSD or nonresponse to treatment. However, a recent study (McReynolds et al., 2017) uncovered some degree of a positive relationship between PTSD symptoms and visual and auditory processing difficulties, such that, as visual and auditory processing difficulties were reduced (i.e., improved attention), PTSD symptoms were also reduced (i.e., improved feelings of general well-being).

\section{Materials}

J\&J EEG stations were used to collect the EEG signals. Impedance was measured to meet the manufacturer's requirements prior to the beginning of each training session. Training was completed using the SmartMind 3 artifact corrected neurofeedback system with a two-channel EEG station (BrainTrain, Inc., North Chesterfield, VA) which continuously filters out frequently occurring, very brief EMG artifacts in real time without interrupting the training program.

Neurofeedback exercises were provided in gamelike format that utilized both visual and auditory reinforcement, as well as graphs and numerical scores to provide positive reinforcement. The first step in the training session was to collect an individual's baseline EEG data in order to determine $z$-score feedback goals for each individual. Based on each individual's performance, they were provided clinically relevant feedback and adjustments were made to the training protocol to optimize their performance. All EEG data were automatically recorded.

\section{Neurofeedback Participants}

The participants for this study were retrospectively identified, using a stratified random sampling method, from an archival database of adults who previously received individualized neurofeedback training within a university-based clinic setting. Only those adults who completed 20 neurofeedback treatment sessions, self-reported as being previously diagnosed with PTSD (confirmed by a licensed clinical psychologist in a university-based setting), and disclosed military status were selected for this study (see Table 4 for demographic details).

Neurofeedback treatment was provided for 33 adults who reported being previously diagnosed with PTSD and reported either military or no military experience ( $n=21$ US military, 20 males, 1 female; $n=12$ nonmilitary, 6 males, 6 females) who completed a total of 20 half-hour sessions of neurofeedback treatment.

Participants were not compensated to participate in the neurofeedback training. This study was approved by the California State University San Bernardino Internal Review Board. Participants were provided with an informed consent process at the initial intake interview, which was conducted by a licensed clinical psychologist.

\section{Neurofeedback Treatment Protocol}

Each participant received an individualized neurofeedback treatment plan based on areas of visual and auditory processing strengths and weaknesses in accordance with software specifications. Treatment was administered on a 
Table 4

Demographic Frequencies $(N=33)$

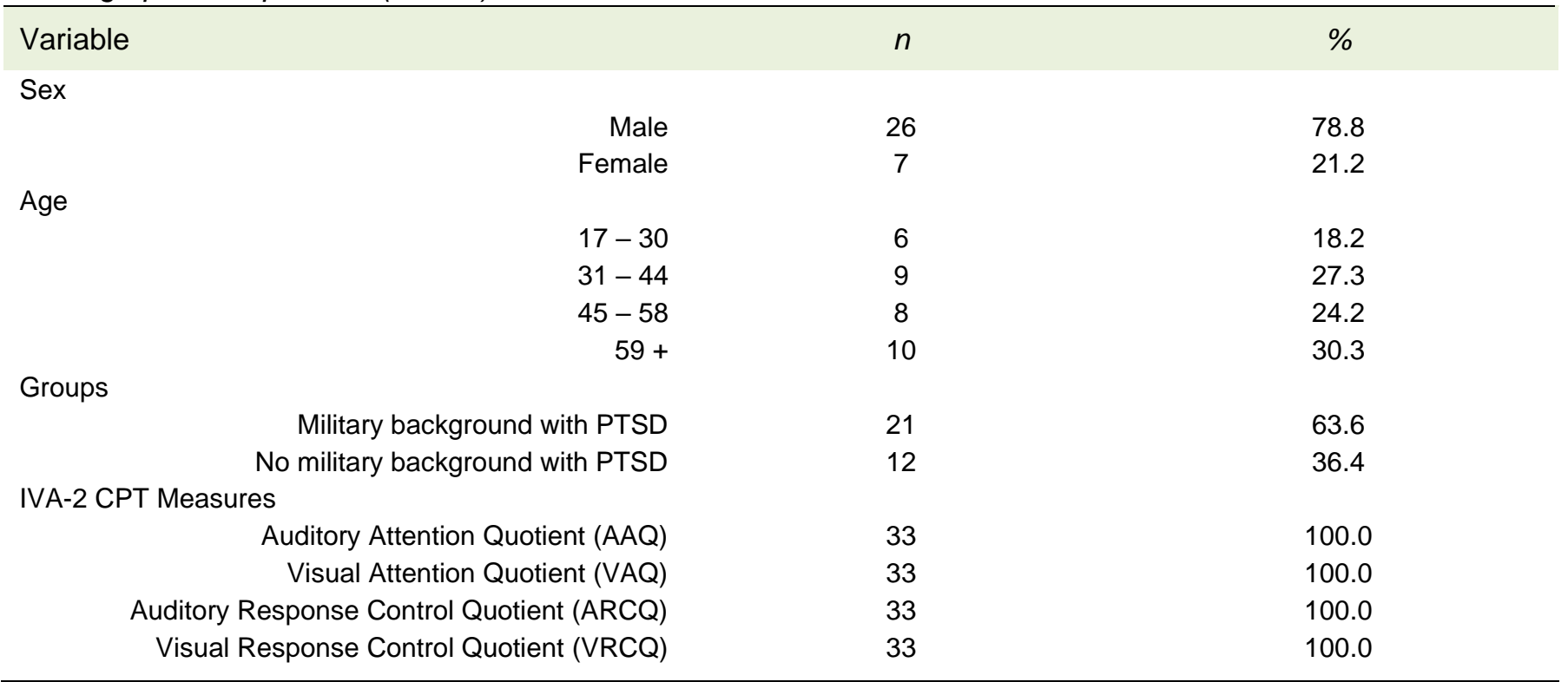

one-to-one basis, in a private room, within a university clinic setting. Therapeutic goals targeted reduction of mental stress related to PTSD symptoms by strengthening visual or auditory attentional functioning. During the first training session, EEG data were collected in accordance with software specifications from each participant at baseline to determine treatment plan and goals. Training parameters were then individually tailored for each participant according to baseline performance.

\section{Neurofeedback Treatment Protocol}

Each participant received an individualized neurofeedback treatment plan based on areas of visual and auditory processing strengths and weaknesses in accordance with software specifications. Treatment was administered on a one-to-one basis, in a private room, within a university clinic setting. Therapeutic goals targeted reduction of mental stress related to PTSD symptoms by strengthening visual or auditory attentional functioning. During the first training session, EEG data were collected in accordance with software specifications from each participant at baseline to determine treatment plan and goals. Training parameters were then individually tailored for each participant according to baseline performance.
Treatments were administered using the SmartMind 3 artifact corrected neurofeedback system with a two-channel EEG station (BrainTrain, Inc., North Chesterfield, VA). Artifact correction lends a unique real-time quality to the SmartMind 3 neurofeedback system by filtering out brief facial activity, frequently occurring eye blinks, and eye movement, without interrupting the training program (Sandford \& Sandford, 2015). Treatment was administered through a $\mathrm{BCl}$ device, utilizing visual and auditory reinforcement as well as graphics and a scoring system to generate positive reinforcement through a feedback loop.

During each training session, neural activity is monitored and recorded from electrodes placed on the scalp. Visual and auditory biofeedback are displayed on a computer monitor in live time, using a simple video game format, which is designed to alter neural signals and activity (Sandford \& Sandford, 2015).

\section{Test Procedures}

Prior to beginning neurofeedback training, each participant underwent an initial comprehensive intake conducted by a licensed clinical psychologist. Following the intake assessment, during the same visit, participants were administered the IVA-2 CPT. Participants who were too severely impaired in attentional functioning to validly respond to either visual or auditory IVA-2 test stimuli were given a 
score of zero for these responses, per test interpretation protocol (Sandford \& Sandford, 2015). Immediately upon completion of testing, a comprehensive report was generated, identifying areas of visual and auditory processing strengths and weaknesses. The clinician reviewed the report with the participant to provide feedback and psychoeducation and to formulate a treatment plan.

Participants were scheduled to attend two half-hour EEG neurofeedback sessions per week over the course of 10 weeks. After completing 20 neurofeedback sessions, the IVA-2 test was readministered.

\section{Measures}

\section{Integrated Visual and Auditory Continual}

Performance Test - Version 2

The IVA-2 CPT has been found to be a reliable and valid measure of visual and auditory attention processing. It is a test of impulsivity and attention that measures responses to 500 intermixed visual and auditory stimuli, which takes about 15 minutes to complete. All scales are reported as standard scores and have a mean of 100 and a standard deviation of 15 (see Appendix A for descriptions of IVA-2 visual and auditory attention and response control scales). There are two validity measures built into the IVA-2 to ensure comprehension of test instructions and consistent response patterns (Sandford \& Sandford, 2015). The global measures of attention used for this study are the Visual Attention Quotient (VAQ) and the Auditory Attention Quotient (AAQ; see Appendix B for descriptions of IVA-2 visual and auditory attention and response control measures).

\section{Visual Attention Quotient (VAQ)}

This measure of attention is made up of three primary visual scales: Vigilance, Speed, and Focus. The Vigilance scale measures errors of omission, the Speed scale measures response time to visual test targets, and the Focus scale measures inconsistency of response time to visual test targets (Sandford \& Sandford, 2015).

\section{Auditory Attention Quotient (AAQ)}

This measure of attention is made up of three primary auditory scales: Vigilance, Speed, and Focus. The Vigilance scale measures errors of omission, the Speed scale measures response time to auditory test targets, and the Focus scale measures inconsistency of response time to auditory test targets (Sandford \& Sandford, 2015).

\section{Auditory Response Control Quotient (ARCQ)}

This measure of response control is made up of three primary auditory scales: Prudence, Consistency, and Stamina. The Prudence scale measures errors of commission, which indicates level of impulsivity and ability to inhibit responses to auditory stimuli. The Consistency scale measures the ability to stay on task by analyzing the general variability of response times. The Stamina scale is used to identify mental fatigue by monitoring auditory processing speed over time and comparing the mean reaction times of correct responses between the beginning portion and end portion of the IVA-2 test (Sandford \& Sandford, 2015).

\section{Visual Response Control Quotient (VRCQ)}

This measure of response control is made up of three primary visual scales: Prudence, Consistency, and Stamina. The Prudence scale measures errors of commission, which indicates level of impulsivity and ability to inhibit responses to visual stimuli. The Consistency scale measures the ability to stay on task by analyzing the general variability of response times. The Stamina scale is used to identify mental fatigue by monitoring auditory processing speed over time and comparing the mean reaction times of correct responses between the beginning portion and end portion of the IVA-2 test (Sandford \& Sandford, 2015).

\section{Data Analyses}

Before running the analyses, tests for multivariate normality, multicollinearity, and outliers were conducted. Outliers were labeled using a boxplot and the interquartile range (IQR); data were transformed and normalized using winsorization (Shete et al., 2004). Using an alpha criterion of .05, a Bonferroni correction was applied across all analyses, determining an alpha of .01 to be adequate in reducing the chance of making a familywise Type I error.

\section{Results}

Descriptive statistics for each one-tailed pairedsamples $t$-test analysis, including pre- and posttreatment IVA-2 scores, are presented in Table 5 (Attention scales) and Table 6 (Response Control scales). To test the first hypothesis, a series of onetailed paired-samples $t$-tests were conducted to test for differences between the means of each Attention and Response Control Quotient scale (AAQ, VAQ, $A R C Q, V R C Q$ ) at baseline and after 20 sessions. 


\begin{tabular}{|c|c|c|c|c|c|}
\hline $\begin{array}{l}\text { Table } 5 \\
\text { Paired sample one-tailed } t \text {-tests compar } \\
\text { neurofeedback sessions }(N=33)\end{array}$ & -2 Atte & ient sc & 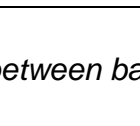 & & 0 \\
\hline IVA-2 Attention Scales & $\begin{array}{c}\text { Baseline } \\
M(S D)\end{array}$ & $\begin{array}{c}20 \text { Sessions } \\
M(S D)\end{array}$ & $\begin{array}{c}\text { Score } \\
\text { Change }\end{array}$ & $\begin{array}{c}p \\
\text { value }\end{array}$ & $\begin{array}{c}\text { Cohen's } \\
d\end{array}$ \\
\hline Visual Attention Quotient Score (VAQ) & $85(24)$ & $97(18)$ & 12 & .000 & .57 \\
\hline Auditory Attention Quotient Score (AAQ) & $84(22)$ & $94(16)$ & 10 & .002 & .52 \\
\hline
\end{tabular}

Note. A Bonferroni correction has been applied for multiple comparisons.

\section{Table 6}

Paired sample one-tailed t-tests comparing Mean (SD) IVA-2 Response Control Quotient scale scores between baseline and after 20 neurofeedback sessions $(N=33)$

\begin{tabular}{llcccc} 
IVA-2 Response Control Scales & Baseline & 20 Sessions & Score & $p$ & Cohen's \\
& $M(S D)$ & $M(S D)$ & Change & value & $d$ \\
Visual Response Control Quotient Score (VRCQ) & $92(22)$ & $96(18)$ & 4 & .184 & .20 \\
Auditory Response Control Quotient Score (ARCQ) & $94(19)$ & $97(14)$ & 3 & .166 & .18 \\
\hline
\end{tabular}

Note. A Bonferroni correction has been applied for multiple comparisons.

As a group (i.e., both military and nonmilitary adults with PTSD), the individuals in this study initially presented with impaired visual and auditory functioning. After 20 half-hour neurofeedback treatment sessions, both their visual and auditory attention abilities improved, falling within the normal range (i.e., defined as a standard score of 77 or higher; Sandford \& Sandford, 2015). On average, change-score differences between pre- and posttreatment IVA-2 attentional scales (i.e., VAQ and $A A Q)$ were clinically significant $(M=11, S D=$ 16; $M=10, S D=18$, respectively), which is defined as a change-score of 8 points or more (McReynolds et al., 2018; McReynolds et al., 2019; Sandford \& Sandford, 2015).

VAQ scores were found to be significantly higher after 20 sessions of neurofeedback treatment from a mean of 86 (slightly to moderately impaired) to 97 (average), an 11-point increase, $t(32)=-4.06, p<$ .001 , Cohen's $d=.52$. AAQ scores were found to be significantly higher after 20 sessions of neurofeedback treatment from a mean of 84 (mildly impaired) to 94 (average), a 10-point increase, $t(32)$ $=-3.21, p<.01$, Cohen's $d=.52$. Both scales of attentional functioning had effect sizes in the medium range demonstrating the clinical efficacy of neurofeedback as a therapeutic intervention for individuals diagnosed with PTSD and presenting with attentional deficits. There were no significant differences between the Visual (VRCQ) and Auditory (ARCQ) Response Control scale scores before treatment and after treatment, $p S>.10(M=4, S D=$ 18 and $M=3, S D=18$, respectively).

To test the second hypothesis that there would be no difference in treatment outcomes among military and nonmilitary adults diagnosed with PTSD, a 2x2 between-subjects factorial repeated measures MANCOVA with Bonferroni correction was performed, predicting posttreatment (i.e., 20 sessions of neurofeedback) IVA-2 scale scores (i.e., $A A Q, V A Q, A R C Q, V R C Q$ ) from group type (i.e., military vs. nonmilitary adults), controlling for age and gender.

\section{Table 7}

MANCOVA Results

$\begin{array}{ccccccc}\text { Predictor } & d f & \text { Multivariate } F & \text { Wilks' } \boldsymbol{P} & \text { Partial } \eta^{2} & p \text { value } \\ \text { Group } & 1,31 & .592 & .938 & .062 & .626 \\ \text { Time } & 1,31 & 1.728 & .944 & .056 & .199 \\ \text { Group * Time } & 1,31 & .045 & .998 & .002 & .834\end{array}$

Note. A Bonferroni correction has been applied for multiple comparisons. Group = military vs. nonmilitary; Time = pre- and posttreatment of 20 neurofeedback sessions. 
As can be seen in Table 7, results indicated that whether or not a person diagnosed with PTSD had military experience was not a significant predictor of overall neurofeedback treatment outcome, $F(1,31)=$ .592 , Wilks' lambda $=.938$, partial $\eta^{2}$ squared $=.062$, $p>.07$.

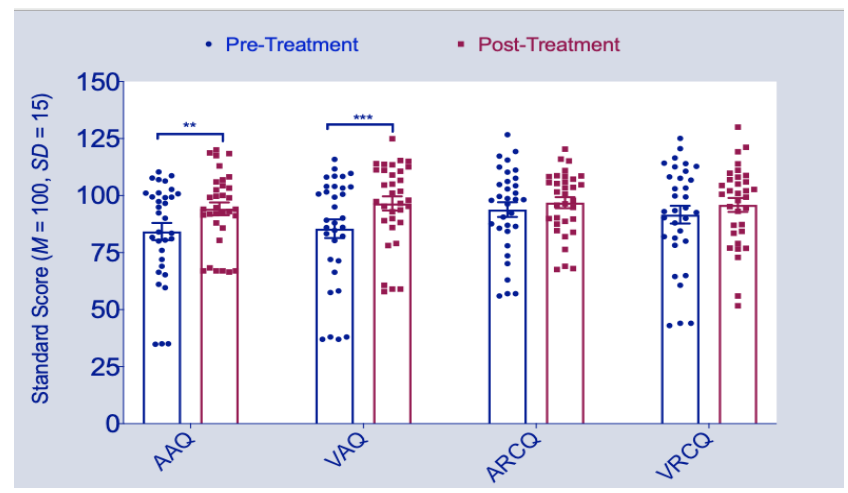

Figure 1. Pre- and posttreatment outcomes. Visual and auditory attention and response control scale score changes between baseline and after 20 neurofeedback sessions. ${ }^{* *} p<.01,{ }^{* * *} p<.001$ denotes statistical significance between pre- and posttreatment.

\section{Discussion}

Findings from the current study indicate that neurofeedback treatment was effective in improving visual and auditory attention for individuals diagnosed with PTSD, regardless if they had military experience or no military experience. To test the first hypothesis, a series of one-tailed paired samples $t$-test were performed to compare the change scores between pre- and posttreatments of 20 neurofeedback sessions, as measured by the IVA-2 on the Auditory Attention Quotient (AAQ), Visual Attention Quotient (VAQ), Attention Response Control Quotient (ARCQ), and Visual Response Control Quotient (VRCQ) scales. To test the second hypothesis, a 2x2 between-subjects factorial multivariate analysis of covariance (MANCOVA) with Bonferroni correction was performed on four dependent variables (i.e., VAQ, AAQ, VRCQ, $A R C Q)$.

Hypothesis one was partially supported because, the change-scores between pre- and posttreatment on the IVA-2 attentional measures of visual and auditory processing (VAQ and $A A Q$ ) indicated statistically significant improvement, while the change-scores between the pre- and posttreatment IVA-2 Visual (VRCQ) and Auditory (ARCQ) Response Control scales did not indicate a significant difference. It should be noted that the data on both response control scales showed an upward change-score trend.

The second hypothesis was supported because there was no difference between treatment outcomes among military and nonmilitary adults diagnosed with PTSD, following 20 sessions of neurofeedback, across all visual and auditory attention and response control scales. Neurofeedback was similarly effective for both military and nonmilitary adults, with the greatest amount of improvement in auditory and visual attention abilities (Figure 1).

Of interest, although both groups had statistically similar treatment outcomes on the $\mathrm{VAQ}$ and $\mathrm{AAQ}$ (i.e., baseline scores were in the impaired range, and posttreatment scores were in the average range), the military group achieved higher change scores overall than the nonmilitary group, such that military adults had lower IVA-2 scores at baseline and higher IVA-2 scores posttreatment than nonmilitary adults. Conversely, on the ARCQ and VRCQ, the nonmilitary group had lower baseline scores and higher IVA-2 scores posttreatment than the military group. Overall, both groups showed similar rates of improvement across all visual and auditory scales, between baseline scores and scores after 20 sessions. These data indicate that 20 sessions of EEG neurofeedback training were similarly effective for both military and nonmilitary adults diagnosed with PTSD.

Through the use of repetition and reinforcement, neurofeedback training creates and strengthens visual and auditory neural connections in the prefrontal cortex. The prefrontal cortex makes key contributions to the limbic system, which is involved in generating emotional responses (Arnsten, 2009; Broderick, 2015; Van Eylen, Boets, Steyaert, Wagemans, \& Noens, 2015), such as the fight or flight response. The prefrontal cortex is the part of the brain responsible for executive functioning, which includes prediction outcomes, determining good and bad, social inhibition, differentiation among conflicting thoughts, determination of future consequences, and interpretation of one's reality (Arnsten, 2009).

Through the strengthening of visual and auditory processing pathways in the prefrontal cortex, neurofeedback trains individuals to self-regulate physiological responses triggered by the limbic system (e.g., stress and anxiety). The more times a brain completes a specific task, the stronger the neural connections become in that pathway each 
successive time. This is known as the Hebbian synaptic plasticity theory, which suggests neurons that fire together, wire together by regulating and adapting a neuron's intrinsic excitability (Butko \& Triesch, 2007).

The aftermath of a traumatic event can result in new neural networks forming, which maintain states of fearfulness, rage, and shame, in perpetuity. The repetitive firing of these networks define trauma, triggering chronic activation of the limbic system. Neurofeedback disrupts and weakens those harmful connections by creating new neural patterns. Improving visual and auditory functioning provides faster cognitive processing of environmental cues, which lends the ability to consider more options of how to respond. Response control and paying attention are stabilizing factors in executive functioning, allowing the limbic system to relax (van der Kolk, 2014).

Healthy executive functioning provides the capacity to organize and plan, to weigh the consequences of one's behaviors, to be cognitively flexible, and to regulate one's emotions. Improving visual and auditory processing systemically affects executive functioning and limbic system activation (van der Kolk, 2014). For this reason, individuals with impaired visual and auditory functioning may not respond to traditional CBT programs by sheer virtue that they lack the fundamental capacity to participate in treatment. Participation in treatment involves higher order complex functioning, such as, learning coping mechanisms, identifying triggers, selfregulation, organization and planning, and regular attendance. Lacking these basic underpinnings of executive functioning, while engaging in trauma reprocessing, can severely activate the limbic system. Without the skills to self-regulate, once the limbic system is activated, a person may experience intense flashbacks, anxiety, and emotional distress for several days following therapy (Fisher et al., 2016). Neurofeedback training offers the brain the ability to self-regulate and achieve a state of stability, while simultaneously weakening the neural networks created by shame, fear, and rage.

\section{Limitations}

Limitations of this study include that the sample was retrospectively identified, participants reported prior PTSD diagnosis, and there was an unequal male to female ratio due to the archival nature of the study. Future studies should examine if improvements in attentional abilities postneurofeedback are associated with reduced PTSD symptoms. Some studies (e.g., McReynolds et al., 2017) have supported this conclusion. Given the critical need for effective, affordable, and accessible PTSD services, future research should aggressively strive to identify factors that influence PTSD treatment response. These data will provide critical information necessary to improve interventions and services for individuals with PTSD.

\section{Conclusion and Future Directions}

The results of this study suggest that EEG neurofeedback therapy is clinically effective for improving visual and auditory attentional functioning in both military and nonmilitary adults. This is crucial information because there continues to be high levels of treatment nonresponse and dropout rates among veterans with PTSD who are participating in CBT based programs. Two-thirds of veterans who complete CBT programs remain in the clinical range for PTSD, with notable attention deficits (Bomyea \& Lang, 2012). Additionally, it is estimated that over $80 \%$ of returning combat veterans who enroll in college on the Gl Bill do not complete their degrees. Reportedly, factors contributing to this dropout rate include problems focusing and paying attention (van der Kolk, 2014). The burden placed on both the individual and the healthcare system, including costs for ongoing care, loss of work, and disability benefits, are rising at an unprecedented rate. In 2012 , the VA spent approximately $\$ 3$ billion and the DOD spent about $\$ 294$ million on PTSD care for service members and veterans (Institute of Medicine, 2014). Treatment outcome research, such as this study, is vital to improve the effectiveness of therapeutic interventions for persons diagnosed with PTSD, particularly within specific populations that have high nonresponse rates, such as veterans.

Many PTSD experts recommend sequenced or phase-based therapeutic interventions that target symptoms which are correlated with PTSD prior to using trauma-focused treatments (Cloitre et al., 2012; Haagen, Smid, Knipscheer, \& Kleber, 2015). Phase-based interventions are important to consider because, without first addressing processing deficits and lack of capacity to self-regulate, harm to the patient can result. Neurofeedback therapy builds a stable cognitive foundation through strengthening visual and auditory neural pathways and enhances the brain's capacity to self-regulate; this is achieved without using talk therapy, accessing traumatic memories, or activating distressing emotions (da Silva-Sauer et al., 2019; McReynolds et al., 2017). 
EEG neurofeedback training may be a fundamental component for the treatment of military adults with PTSD. The mechanisms of EEG neurofeedback are currently being studied in the field (da Silva-Sauer et al., 2019; Hammond, 2011; McReynolds et al., 2017, 2018; van der Kolk, 2014), making it a viable option as a first-line intervention for people diagnosed with PTSD. Future work is needed to explore ways to enhance treatment outcome through complementary pairing of EEG neurofeedback training with other therapeutic interventions. Knowledge regarding the mechanisms (e.g., use of neuroimaging, calcium based pre- and postsynaptic neuron activity, spiketiming-dependent plasticity; Schaefer et al., 2000; Vignoud et al., 2018) by which neurofeedback intervention is effective would assist in developing an individualized treatment plan that includes an appropriate level of sequenced engagement based on capacity (e.g., neurofeedback training, selfregulation, skill building, behavioral activation, trauma reprocessing).

Examining the mechanisms of therapeutic treatment is necessary for the proper treatment of impulsivity and inattention, in the context of trauma, and will play a large role in preventing patient harm. Activation of specific mechanisms may be detrimental to the mental health of persons who lack the cognitive capacity to self-regulate, which is why research needs to be conducted on an individuallevel treatment basis through randomized control trials (RCTs; Bomyea \& Lang, 2012). Strengthening the visual and auditory pathways, and improving executive functioning through neurofeedback training, may influence how well a person responds to trauma reprocessing and to what extent they can achieve homeostasis after being severely dysregulated from talk therapy (Fisher et al., 2016). Targeting and improving visual and auditory processing deficits through neurofeedback training may not only predict treatment outcome for subsequent trauma-focused therapies but may also predict how well a person will function in relationships, in school performance, and at work (Fisher et al., 2016; McReynolds et al., 2018; McReynolds et al., 2019).

Given the critical need for effective, affordable, and accessible PTSD services, future research should aggressively strive to identify factors that influence PTSD treatment response, as well as determine which underlying mechanisms and individual characteristics explain how these factors operate. One way to do this would be to explore treatment outcomes when combining neurofeedback training with trauma-focused therapy (e.g., using neurofeedback training as a prerequisite to talk therapy). Strengthening the visual and auditory processing pathways through EEG neurofeedback training, may increase the chances for a nonresponder to successfully engage in, and benefit from, trauma-focused treatment protocols.

\section{Author Disclosure}

Authors have no grant support, financial interests, or conflicts of interest to disclose.

\section{References}

American Psychiatric Association. (2013). Diagnostic and statistical manual of mental disorders (5th ed.). Washington, DC: Author.

Arnsten, A. (2009). Stress signalling pathways that impair prefrontal cortex structure and function. Nature Reviews Neuroscience, $10(6), \quad 410-422 . \quad$ https://doi.org/10.1038 /nrn2648

Bomyea, J., \& Lang, A. J. (2012). Emerging interventions for PTSD: Future directions for clinical care and research. Neuropharmacology, 62(2), 607-616. https://doi.org/10.1016 /j.neuropharm.2011.05.028

Boscariol, M., Garcia, V. L., Guimarães, C. A., Montenegro, M. A., Hage, S. R. V., Cendes, F., \& Guerreiro, M. M. (2010). Auditory processing disorder in perisylvian syndrome. Brain and Development, 32(4), 299-304. https://doi.org/10.1016 /j.braindev.2009.04.002

Broderick, P. C. (2015). The life span: Human development for helping professionals (4th ed.). New York, NY: Pearson.

Butko, N. J., \& Triesch, J. (2007). Learning sensory representations with intrinsic plasticity. Neurocomputing, 70(7-9), $\quad 1130-1138 . \quad$ https://doi.org/10.1016 /j.neucom.2006.11.006

Choudhury, M., \& Sanju, H. K. (2019). Central auditory processing disorder (CAPD) in schoolgoing children. Otolaryngology Open Journal, SE(1), S15-S19. https://doi.org/10.17140/OTLOJ-SE-1-104

Cloitre, M., Courtois, C. A., Ford, J. D., Green, B. L., Alexander, P., Briere, J., ... van der Hart, O. (2012). The ISTSS expert consensus treatment guidelines for complex PTSD in adults. Journal of Traumatic Stress, 24(6), 615-627.

Crocq, M. A., \& Crocq, L. (2000). From shell shock and war neurosis to posttraumatic stress disorder: A history of psychotraumatology. Dialogues in Clinical Neuroscience, 2(1), 47-55. https://doi.org/10.31887/dcns.2000.2.1/macrocq

da Silva-Sauer, L., de la Torre-Luque, A., Silva, J. S. C., \& Fernández-Calvo, B. (2019). New perspectives for cognitive rehabilitation: Could brain-computer interface systems benefit people with dementia? Psychology and Neuroscience, 12(1), 25-37. https://doi.org/10.1037/pne0000154

DeAngelis, T. (2018). Tuning in to our amazing auditory system. Monitor on Psychology, 49(7), 64.

Feduccia, A. A., \& Mithoefer, M. C. (2018). MDMA-assisted psychotherapy for PTSD: Are memory reconsolidation and fear extinction underlying mechanisms? Progress in NeuroPsychopharmacology and Biological Psychiatry, 84(Part A), 221-228. https://doi.org/10.1016/j.pnpbp.2018.03.003

Fisher, S. F., Lanius, R. A., \& Frewen, P. A. (2016). EEG neurofeedback as adjunct to psychotherapy for complex developmental trauma-related disorders: Case study and treatment rationale. Traumatology, 22(4), 255-260. https://doi.org/10.1037/trm0000073

Ghazanfar, A. A., \& Schroeder, C. E. (2006). Is neocortex essentially multisensory? Trends in Cognitive Sciences, 10(6), 278-285. https://doi.org/10.1016/j.tics.2006.04.008 
Haagen, J. F. G., Smid, G. E., Knipscheer, J. W., \& Kleber, R. J. (2015). The efficacy of recommended treatments for veterans with PTSD: A metaregression analysis. Clinical Psychology Review, 40, 184-194. https://doi.org/10.1016 /j.cpr.2015.06.008

Hammond, D. C. (2011). What is neurofeedback: An update. Journal of Neurotherapy, 15(4), 305-336. https://doi.org $/ 10.1080 / 10874208.2011 .623090$

Herwig, U., Lutz, J., Scherpiet, S., Scheerer, H., Kohlberg, J., Opialla, S., ... Brühl, A. B. (2019). Training emotion regulation through real-time $\mathrm{fMRI}$ neurofeedback of amygdala activity. Neurolmage, 184, 687-696. https://doi.org/10.1016 /j.neuroimage.2018.09.068

Institute of Medicine. (2014). Treatment for posttraumatic stress disorder in military and veteran populations: Final assessment. Washington, DC: The National Academies Press. https://doi.org/10.17226/18724

Janarthanan, S. D. (2017). Visual processing disorder in children. Ophthalmology Open Journal, 2(2), 45-47. https://doi.org /10.17140/ooj-2-113

La Marca, J. P., Cruz, D., Fandino, J., Cacciaguerra, F. R., Fresco, J. J., \& Guerra, A. T. (2018). Evaluation of artifactcorrected electroencephalographic (EEG) training: A pilot study. Journal of Neural Transmission, 125(7), 1087-1097. https://doi.org/10.1007/s00702-018-1877-1

Li, K., Kadohisa, M., Kusunoki, M., Duncan, J. A., Bundesen, C., \& Ditlevsen, S. (2018). Distinguishing between parallel and serial processing in visual attention from neurobiological data. bioRxiv, 383596. https://doi.org/10.1101/383596

Litz, B. T., Berke, D. S., Kline, N. K., Grimm, K., RusowiczOrazem, L., Resick, P. A., ... Peterson, A. L. (2019). Patterns and predictors of change in trauma-focused treatments for war-related posttraumatic stress disorder. Journal of Consulting and Clinical Psychology, 87(11), 1019-1029. https://doi.org/10.1037/ccp0000426

McReynolds, C. J., Bell, J., \& Lincourt, T. M. (2017). Neurofeedback: A noninvasive treatment for symptoms of posttraumatic stress disorder in veterans. NeuroRegulation, 4(3-4), 114-124. https://doi.org/10.15540/nr.4.3-4.114

McReynolds, C., Britt, C., \& Villalpando, L. (2019). Identifying auditory and visual processing difficulties in school-aged children with ADHD. In P. Cook (Ed.), Discovering New Educational Trends (V3): A Symposium in Belize, Central America (pp. 2-37). Newcastle upon Tyne, UK: Cambridge Scholars Publishing.

McReynolds, C. J., Villalpando, L. S., \& Britt, C. E. (2018). Using neurofeedback to improve ADHD symptoms in school-aged children. NeuroRegulation, 5(4), 109-128. https://doi.org /10.15540/nr.5.4.109

Musiek, F. E., Baran, J. A., Bellis, T. J., Chermak, G. D., Hall III, J. W., Keith, R. W., ... Nagle, S. (2010). Guidelines for the Diagnosis, Treatment and Management of Children and Adults with Central Auditory Processing Disorder. Reston, VA: American Academy of Audiology. Retrieved from https://audiology-web.s3.amazonaws.com/migrated/CAPD Guidelines 8-2010.pdf 539952af956c79.73897613.pdf

Panisch, L. S., \& Hai, A. H. (2020). The effectiveness of using neurofeedback in the treatment of post-traumatic stress disorder: A systematic review. Trauma, Violence, \& Abuse, 21(3), 541-550. https://doi.org/10.1177/1524838018781103

Quevedo, K., Liu, G., Teoh, J. Y., Ghosh, S., Zeffiro, T., Ahrweiler, N., ... Paret, C. (2019). Neurofeedback and neuroplasticity of visual self-processing in depressed and healthy adolescents: A preliminary study. Developmental Cognitive Neuroscience, 40, 100707. https://doi.org/10.1016 /j.dcn.2019.100707
Recanzone, G. H., \& Cohen, Y. E. (2010). Serial and parallel processing in the primate auditory cortex revisited. Behavioural Brain Research, 206(1), 1-7. https://doi.org /10.1016/j.bbr.2009.08.015

Sandford, J., \& Sandford, S. (2015). IVA-2 Integrated Visual and Auditory Continuous Performance Test manual. North Chesterfield, VA: BrainTrain, Inc.

Schaefer, M. L., Wong, S. T., Wozniak, D. F., Muglia, L. M., Liauw, J. A., Zhuo, M., ... Muglia, L. J. (2000). Altered stressinduced anxiety in adenylyl cyclase type VIII-deficient mice. The Journal of Neuroscience, 20(13), 4809-4820. https://doi.org/10.1523/jneurosci.20-13-04809.2000

Serafini, G., Engel-Yeger, B., Vazquez, G. H., Pompili, M., \& Amore, M. (2017). Sensory processing disorders are associated with duration of current episode and severity of side effects. Psychiatry Investigation, 14(1), 51-57. https://doi.org/10.4306/pi.2017.14.1.51

Shete, S., Beasley, T. M., Etzel, C. J., Fernández, J. R., Chen, J., Allison, D. B., \& Amos, C. I. (2004). Effect of winsorization on power and type 1 error of variance components and related methods of QTL detection. Behavior Genetics, 34(2), 153159. https://doi.org/10.1023/B:BEGE.0000013729.26354.da

Solberg Økland, H., Todorović, A., Lüttke, C. S., McQueen, J. M., \& de Lange, F. P. (2018). Predicting audiovisual speech: Early combined effects of sentential and visual constraints. BioRxiv, 360578. https://doi.org/10.1101/360578

Taneja, N. (2017a). A mini review on differential overview of central auditory processing disorder (CAPD) and attention deficit hyperactivity disorder (ADHD). Otolaryngology Open Journal, $S E(1)$, S20-S23. https://doi.org/10.17140/OTLOJSE-1-105

Taneja, N. (2017b). Comprehensive CAPD intervention approaches. Otolaryngology Open Journal, SE(1), S24-S28. https://doi.org/10.17140/OTLOJ-SE-1-106

Thomas, J., \& Mack, M. (2010). Auditory processing disorder and reading difficulties. Victoria, Australia: Listen and Learn Centre. Retrieved from https://www.listenandlearn.com.au /wp-content/uploads/2014/10/research_APD1.pdf

Thorne, J. D., \& Debener, S. (2014). Look now and hear what's coming: On the functional role of cross-modal phase reset. Hearing Research, 307, 144-152. https://doi.org/10.1016 /j.heares.2013.07.002

van der Kolk, B. A. (2014). The body keeps the score: Brain, mind, and body in the healing of trauma. New York, NY: Viking.

van der Kolk, B. A., Hodgdon, H., Gapen, M., Musicaro, R., Suvak, M. K., Hamlin, E., \& Spinazzola, J. (2016). A randomized controlled study of neurofeedback for chronic PTSD. PLOS ONE, 11(12), e0166752. https://doi.org/10.1371 /journal.pone.0166752

Van Eylen, L., Boets, B., Steyaert, J., Wagemans, J., \& Noens, I. (2015). Executive functioning in autism spectrum disorders: Influence of task and sample characteristics and relation to symptom severity. European Child \& Adolescent Psychiatry, 24(11), 1399-1417. https://doi.org/10.1007/s00787-015-0689-

Vignoud, G., Venance, L., \& Touboul, J. D. (2018). Interplay of multiple pathways and activity-dependent rules in STDP. PLoS Computational Biology, 14(18), e1006184. https://doi.org/10.1371/journal.pcbi.1006184

Received: October 28, 2020

Accepted: December 13, 2020

Published: December 29, 2020 


\section{Appendices}

\section{Appendix A}

Description of IVA-2 visual and auditory primary scales

\begin{tabular}{l|l}
\hline Attention Scales & IVA-2 Description of Primary Attention Scales \\
\hline Vigilance & $\begin{array}{l}\text { Measure of inattention as evidenced by two different types of errors of } \\
\text { omission }\end{array}$ \\
\hline Focus & $\begin{array}{l}\text { Reflects the total variability of mental processing speed for all correct } \\
\text { responses }\end{array}$ \\
\hline Speed & Reflects the average reaction time for all correct responses \\
\hline Response Control Scales & IVA-2 Description of Primary Response Control Scales \\
\hline Prudence & $\begin{array}{l}\text { Measure of impulsivity and response inhibition as evidenced by three } \\
\text { different types of errors of commission }\end{array}$ \\
\hline Consistency & $\begin{array}{l}\text { Measures the general reliability and variability of response times and is used } \\
\text { to help measure the ability to stay on task }\end{array}$ \\
\hline Stamina & $\begin{array}{l}\text { Compares the mean reaction times of correct responses during the first } 100 \\
\text { trials to the last } 100 \text { trials; this score is used to identify problems related to } \\
\text { sustaining attention and effort over time }\end{array}$ \\
\hline
\end{tabular}

Source: Sandford \& Sandford, 2015.

\begin{tabular}{l|l}
\hline \begin{tabular}{l} 
Appendix B \\
Description of IVA-2 visual and auditory global composite measures \\
\hline IVA-2 Measures
\end{tabular} & IVA-2 Description of Measures \\
\hline AAQ & Based on equal measures of auditory Vigilance, Focus, and Speed scales \\
Auditory Attention Quotient & Derived from auditory Prudence, Consistency, and Stamina scales \\
\hline ARCQ & \\
Auditory Response Control Quotient & Based on equal measures of visual Vigilance, Focus, and Speed scales \\
\hline VAQ & \\
Visual Attention Quotient & Derived from visual Prudence, Consistency, and Stamina scales \\
\hline VRCQ & \\
Visual Response Control Quotient &
\end{tabular}

